\title{
As mulheres entre a libertação e a renovação na obra lacerdiana
}

\author{
Women between liberation and renewal in the lacerdiana work
}

Las Mujeres entre la liberación y la renovación em la obra lacerdiana

LACERDA DE MOURA, Maria. Renovação, 1919. Edição Fac-Simile. Fortaleza: Edições UFC, 2015.

\begin{abstract}
Patrícia Lessa $^{\mathrm{a}} \mathbb{D}^{\mathrm{D}}$; Ana Carolina Lamosa Paes ${ }^{\mathrm{b}}$
${ }^{a}$ Doutora em História na área de Estudos Feministas e de gênero (UnB) e pós-doutora em Letras (UFF). Líder criadora do Grupo de Estudos nas Pedagogias do Corpo e da Sexualidade (Gepecos), atualmente leciona na Universidade Estadual de Maringá, Maringá, PR, Brasil. - E-mail: patricialessa13@gmail.com

${ }^{\text {b }}$ Graduada em História e Mestranda em História (UEM), integrante do Grupo de Estudos nas Pedagogias do Corpo e da Sexualidade (Gepecos), realizou pesquisa de iniciação científica sob a orientação de Patrícia Lessa com o título: “A construção social da prostituição na obra de Gabriela Leite” na Universidade Estadual de Maringá, PR, Brasil. - E-mail: anacapaes@hotmail.com
\end{abstract}

\section{Como citar o artigo:}

LESSA, Patrícia. PAES, A. C. L. As mulheres entre a libertação e a renovação na obra lacerdiana. Revista de Ciências Humanas, Florianópolis, v. 52, 2018 DOI: 10.5007/2178-4582.2018.45982

Renovação, publicado em 1919, é o segundo livro da autora, ainda no início de sua trajetória como escritora e conferencista anarquista. Maria Lacerda de Moura nasceu em 16 de maio de 1887 em Manhuaçu (MG), casou aos 17 anos, se divorciou e não teve filhos naturais. Adotou Jair e Carminda, para quem dedica o livro Renovação. Ela escreve: "aos meus filhinhos adoptivos-nascidos da maternidade espiritual do meu ser, da necessidade que sente o coração feminino de transbordar o seu affecto em outros affectos" (p. 41). A autora, além disso, deixou uma extensa bibliografia entre livros, textos jornalísticos e conferências. Seus escritos, à época, circularam no país e no exterior. Em suas obras, a condição feminina está no centro das reflexões críticas, posicionando-se contra o autoritarismo do Estado, da instituição religiosa cristã e da família. Foi uma pacifista, antifascista, anticlerical, individualista, anarquista, abraçou ideias neomalthusianas, sendo influenciada na 
juventude pelo positivismo e pelo cientificismo. Foi uma intelectual ávida pelo conhecimento, autodidata, desenvolvendo estudos em vários campos, entre eles a filosofia, a astrologia e, principalmente, a educação.

A inciativa dos organizadores Adelaide Gonçalves, Allyson Bruno e Camila Queiroz se soma aos trabalhos de Miriam Moreira Leite e de Margareth Rago, com a intenção de dar voz aos trabalhos da feminista libertária. Dizem: "sua obra permanece, em parte, negligenciada no tempo, inclusive n'algumas versões do feminismo contemporâneo, pouco dispostas a considerar o alcance de suas proposições” (p. 7). A reimpressão fac-símile é composta por uma apresentação escrita pelas organizadoras, ambas com formação em História, cujo texto busca reconstituir a trajetória da educadora libertária. $\mathrm{O}$ texto inicia com o itinerário da experiência autodidata de Maria Lacerda e apresenta seu escrito marcado pela narrativa panfletária e formato de manifesto, fazendo críticas à representação parlamentar, ao feminismo liberal, ao capitalismo e à propriedade privada.

O livro Renovação está dividido em seis capítulos: Feminismo, O Suffragio Feminino, A Religião, Solidariedade, Seducções e A Educação Nova. A organização das ideias marca sua preocupação com as assimetrias nas relações masculino/feminino e os desdobramentos da exploração capitalista, centrando sua crítica no feminismo liberal, que tinha uma preocupação relacionada às mulheres burguesas. Por isso, para a autora, o sufrágio era um passo para algo maior: a libertação das mulheres de todas as classes sociais, principalmente das trabalhadoras relegadas à jornadas de trabalho exaustivas, salários menores que os dos homens e ao trabalho doméstico, visto como servidão voluntária baseada nos princípios da família burguesa.

Na primeira parte da obra, a autora explora o conceito de feminismo chamando as mulheres para a busca de aspirações racionalistas e solidárias, pois "depende disso o futuro das nossas filhas". Para ela, o capitalismo cresceu alimentado pelo individualismo e, em consequência, a emergência do feminismo, ao questionar as bases da desigualdade entre mulheres e homens no trabalho e na vida doméstica, colaborou para a luta coletiva das mulheres. Diz: "o feminismo irrompe de todos os lados. Força alguma será capaz de contê-lo. É tempo" (p. 63). Para entender o feminismo em Maria Lacerda é importante destacar que ela via na prostituição uma miséria construída pelo capitalismo, ou seja, ela se opunha a ideia de que a mulher casada deveria ser uma puritana assujeitada ao marido e incumbida dos cuidados dos filhos e do lar, enquanto o papel das prostitutas seria satisfazer desejos desses mesmos maridos. A diferença entre elas cria um abismo entre desiguais papeis sociais destinados às mulheres. As primeiras incumbidas do papel de devoção ao marido e à família burguesa, a segunda relegada ao papel de mercadoria, usada como carne barata e, logo em seguida, abandonada às doenças e à miséria. Sua visão é claramente marcada pela crítica à sujeição das mulheres e, 
portanto, sua luta é chamar a atenção das mesmas para a importância do estudo para a conquista da libertação feminina.

Na segunda parte, destinada à discussão do "Suffragio Feminino", ela reforça a luta libertária diante do avançar de um feminismo liberal baseado em princípios burgueses de negociação com o opressor, o homem liberal, burguês e explorador. Nessa perspectiva não havia espaço para pensar na condição das mulheres das classes operárias. Geralmente relegadas à longas jornadas de trabalho, desde a infância até a morte, pouco tempo teriam para uma formação e instrução, o que dificultava sua emancipação e, até mesmo, o exercício do voto consciente. Assim, sua aspiração era alcançar a mulher trabalhadora: "Não escrevo para as poucas mulheres que lêem [...] e sim para as muitas que não puderam receber uma instrucção sólida, para as que não podem ter bibliotecas, as que não tiveram professores, as que não foram habituadas a pensar" (p. 147).

No capítulo destinado à religião ela inicia afirmando que esta é um dos grandes empecilhos ao progresso das mulheres. Sua crítica é dirigida ao fanatismo religioso presente na classe média e dá luz aos habituais comportamentos de beatismo e superstições alimentadas nos círculos das escolas religiosas. Além disso, sua crítica ao pensamento judaico-cristão europeu, fundado em princípios nacionalistas, patrióticos, de ódio aos outros povos é a prova da incoerência das instituições religiosas. Estas instituições estavam, sim, comprometidas com o poder do Estado totalitário, diz ela: "Mas que juízo fazem de Deus? Como se havia Elle de repartir entre alemães e aliados” (p. 157). Ao final do capítulo ela afirma respeitar a religião, que não é nem o clero nem o sectarismo, mas uma preocupação com a elevação da humanidade, da beleza e da contemplação. Relata em um subcapítulo nomeado de Liga Fraternista Internacional, uma comemoração das lojas teosóficas no Rio de Janeiro referente à Fraternidade Universal. Assim como no subcapítulo O Primeiro Congresso de Religiões no Brasil, relata o evento realizado no Rio de Janeiro, em 01 de janeiro de 1918, durante a comemoração da Fraternidade Universal.

O capitulo três chama-se Solidariedade. Logo em seu início, Lacerda reafirma constantemente a necessidade vital de que as mulheres busquem sua união para que possam se fortalecer e, assim, buscar meios de firmar seu espaço na sociedade, de forma participativa e solidária com as mulheres e crianças independentemente da classe social. Para a autora, o papel social ocupado pelas mulheres era secundário e, por isso, essas eram coadjuvantes de sua própria história. Sua proposta, então, era que as mulheres deveriam se ajudar umas às outras, para se livrar das amarras masculinas, seja enquanto filantropas ou seja em caráter de comunidades de ajuda mútua. Ao discorrer a respeito das questões de higiene, ela chama atenção para o desconhecimento da mulher com relação à saúde de seu corpo, dos cuidados com a gravidez e os riscos que correm ao submeter-se a serviços médicos de baixa qualidade e demasiada truculência. Esta situação está ligada diretamente à condição social e 
atinge fortemente pobres que não têm alimentação razoável, conhecimento acerca da saúde e cuidados em geral. Seu apelo é dirigido às mulheres burguesas, pois mulheres com regalias têm o dever de compadecer-se e envergonhar-se em dar fortunas para adquirir vestidos ou joias enquanto outras morrem pela fome ou doenças.

O capítulo seguinte chama-se Seduç̧ões. A autora começa contando a história de um trabalhador que adota uma criança abandonada, fruto de um envolvimento fora do casamento. Sempre muito enfática a respeito do resguardo da mulher com relação ao homem, Lacerda adverte sobre como esses envolvimentos são depreciativos para a mulher e praticamente sem consequências para os homens, sempre protegidos pela sociedade e pelas leis. Atribuindo a prostituição à pobreza, Lacerda escreve sobre o desenvolvimento do imaginário feminino acerca do feminismo e conclui que é preciso buscar a emancipação e libertar-se do preconceito, avançando para a conquista de autonomia para mulheres de todas as camadas sociais. Acerca do amor livre, diz que quanto mais a mulher torna-se intelectualizada, mais complexo é o relacionar-se; torna-se mais ressabiada. Acredita que conforme estes patamares vão sendo atingidos, questões relativas às mulheres em sociedade também serão sanadas, tal qual a prostituição, "o mercado da carne moça das mulheres". Por fim, neste capitulo ela ainda escreve sobre o suicídio das mulheres que, em sua grande maioria, são pobres e traídas pelos homens. Lacerda nos diz que a mulher deve render-se a emancipação feminina e lutar por ela, sem desistir. Entregar-se à morte é sucumbir ao desespero e fraqueza, seja do corpo ou da alma.

No último capítulo, A Educação Nova, a autora disserta sobre a educação na formação do indivíduo. Para ela, é importante respeitar a individualidade da criança. No sistema de ensino da época, ela via graves defeitos como a falta de didática dos professores e a ignorância a respeito de processos inovadores para auxiliar no processo educacional. A partir de seu ponto de vista, a legislação do ensino pouco fez pela educação, já que as leis não são capazes de alterar hábitos costumeiros, e os acadêmicos estavam mais preocupados com o próprio status quo do que com a transformação na educação. Lacerda conta que nunca se filiou a nenhum partido, já que não se sentia contemplada em seus ideais revolucionários. Enquanto feminista, a autora busca combater a opressão feminina e coloca essa questão antes da própria luta de classes. A educação é o grande fator de renovação, segundo a autora. O conhecimento, não só acadêmico mas da convivência social, pode ser fundamental na desconstrução da opressão entre sexos. Quem deve organizar a própria revolução é a mulher e esta só pode fazê-lo se obtiver conhecimento. A educação feminina é a chave e o conhecimento do mundo é a forma ideal de adquiri-la, observando as milhares de mulheres ultrajadas e subjugadas.

Por fim, Maria Lacerda chama a atenção mais uma vez para a necessidade de levantar-se contra as formas de governo, dos homens e de seus costumes, principalmente com relação à mulher, 
que era vista como fraca. A união das mulheres poderia fazer delas um corpo único e voraz em busca de seus direitos. Poucos anos depois da publicação de Renovação, a autora vê a ascensão do fascismo na Itália, que influencia o Brasil com projetos patrióticos e autoritários. Endurece, então, as críticas ao autoritarismo do Estado. Na época em que Getúlio Vargas assume o poder, a autora marca sua produção com uma crítica destinada, também, aos mecanismos de poder da conjuntura militarizada financiada pelo fascismo italiano, que incitava a adoção de uma educação religiosa, doutrinária, dogmática e domesticadora. O nacionalismo e o patriotismo do Estado brasileiro seriam alguns dos alvos da crítica lacerdiana nas obras seguintes. Lacerda foi uma escritora libertária incansável e a obra ora resenhada é apenas o início de uma longa e forte trajetória militante e intelectual.

\section{REFERÊNCIAS}

LACERDA DE MOURA, Maria. Renovação, 1919. Edição Fac-Simile. Fortaleza: Edições UFC, 2015. (Original publicado em 1919. Belo Horizonte: Tip. Athene)

$\begin{array}{ll}\text { Histórico } & \text { Recebido em: 2-8-2016 } \\ & \text { Aceito em: 4-10-2018 }\end{array}$ 